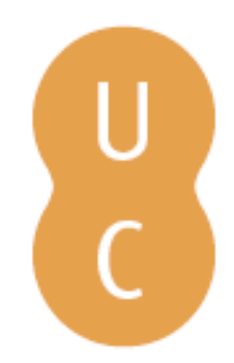

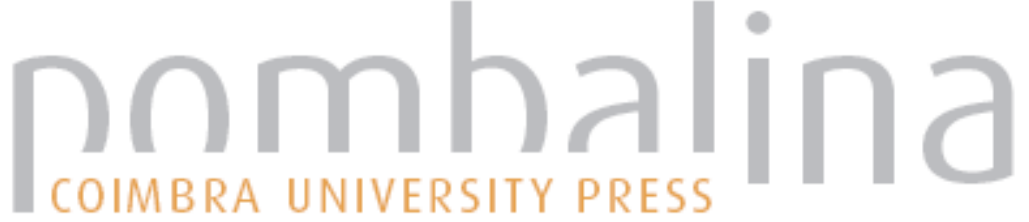

\section{Estado e igreja depois do 25 de Abril}

\author{
Autor(es): $\quad$ Moreira, Adriano
}

Publicado por: Imprensa da Universidade de Coimbra

URL

persistente:

URl:http://hdl.handle.net/10316.2/30087

DOI:

DOI:http://dx.doi.org/10.14195/978-989-26-0310-0_6

Accessed : $\quad$ 26-Apr-2023 11:11:28

A navegação consulta e descarregamento dos títulos inseridos nas Bibliotecas Digitais UC Digitalis, UC Pombalina e UC Impactum, pressupõem a aceitação plena e sem reservas dos Termos e Condições de Uso destas Bibliotecas Digitais, disponíveis em https://digitalis.uc.pt/pt-pt/termos.

Conforme exposto nos referidos Termos e Condições de Uso, o descarregamento de títulos de acesso restrito requer uma licença válida de autorização devendo o utilizador aceder ao(s) documento(s) a partir de um endereço de IP da instituição detentora da supramencionada licença.

Ao utilizador é apenas permitido o descarregamento para uso pessoal, pelo que o emprego do(s) título(s) descarregado(s) para outro fim, designadamente comercial, carece de autorização do respetivo autor ou editor da obra.

Na medida em que todas as obras da UC Digitalis se encontram protegidas pelo Código do Direito de Autor e Direitos Conexos e demais legislação aplicável, toda a cópia, parcial ou total, deste documento, nos casos em que é legalmente admitida, deverá conter ou fazer-se acompanhar por este aviso. 


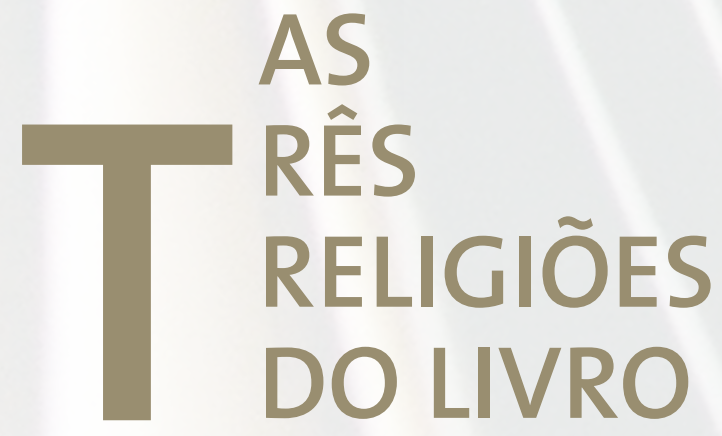

Anselmo Borges

João Gouveia Monteiro

COORDENAÇÃO 


\section{Adriano Moreira 21}

\section{ESTADO E IGREJA DEPOIS DO 25 DEABRIL}

O 25 de Abril é uma data de referência essencial na história portuguesa, mas é, no que toca ao Império Euromundista, o ponto final desse sistema, que esgotou as suas capacidades de manutenção e funcionamento com a guerra civil que mais uma vez envolveu os europeus, os quais não tinham sido atacados por qualquer inimigo externo: não havia Turcos às portas de Viena.

Tomando essa data como referência para o tema das relações entre o Estado e a Igreja, tento reunir algumas notas da memória política nacional que estiveram activas no desenrolar do processo. Em primeiro lugar, a percepção republicana de 1910, presente no ideário da oposição ao regime corporativo da Constituição do Estado Novo, e que tinha Afonso Costa como principal referência de estadista ao qual se atribuiu o objectivo de eliminar o Catolicismo em duas gerações. Tudo resumido na extinção da vinculação recíproca de Estado e Igreja da Monarquia, e da influência da Igreja na sociedade civil. O Estado laico foi a expressão da moderação daquele legado que sobreviveu no republicanismo do 25 de Abril, levantando, não apenas neste aspecto, uma barreira definitiva a visões de futuro mais inspiradas pelo leste da guerra-fria.

Por seu lado, facto evidente nas celebrações do Duplo Centenário, o da Fundação do Reino e o da Restauração, o Vaticano naquela data, já tão próxima do fim do Império Euromundista, vaticinava expressamente que Portugal continuaria a missão e responsabilidade histórica da evangelização nas terras e povos que os europeus se tinham habituado a chamar "o resto

21 Presidente da Academia das Ciências de Lisboa e Presidente do Conselho Geral da Universidade Técnica de Lisboa. 
do mundo"; e também da conclusão do Concílio do Vaticano II (1961), que vigorosamente afirmou a distância da Igreja Católica em relação a todos os regimes políticos, convidando porém todos a recolherem ensinamentos da sua doutrina: as hoje praticamente desaparecidas Democracias Cristãs europeias, com Schuman na França, De Gasperi na Itália, e Adenauer na Alemanha, seriam as responsáveis principais pelos alicerces da União Europeia, projecto renovador da Europa destroçada pela II Guerra Mundial: é de notar que seria em Portugal que a força política que se proclamou tributária das Democracias Cristãs europeias seria a que teria menor dimensão e peso no que foi chamado o Arco Constitucional, e no governo, embora a sociedade civil tivesse, naquela data, uma identificação maioritária com o catolicismo, somando os que se proclamaram praticantes com os que reconheciam a filiação cultural, mas que se declaravam não praticantes.

Tendo sido o 25 de Abril um movimento aderente às autodeterminações dos povos submetidos ao colonialismo ocidental, é exigente meditar sobre a presença daquilo que o Vaticano considerou missão portuguesa em 40, com expressão formal no Acordo Missionário, e sobre a corrente reformista que cresceu dentro da Igreja, nesse tempo.

A questão diz respeito ao Acordo Missionário que, convencionado entre o Estado Novo e a Santa Sé, regulava a acção missionária nos territórios coloniais, ficando para segundo plano, nesta reunião, a questão do Padroado do Oriente em que o país tinha sido desconsiderado, tendo em vista as circunstâncias da época, no que toca às relações entre o Estado e a Igreja. Refiro-me, por selecção de factos, aos casos de D. António Ferreira Gomes, Bispo do Porto, cuja saga, destacando-se o exílio forçado, e a doutrinação filiada na doutrina conciliar, foi integrada no legado definido pela circunstância complexa de 1974. Parece-me de interesse notar, e averiguar, as razões pelas quais o seu legado foi titulado pela corrente social-democrática do novo regime, tendo sido evitado, com êxito, que tal legado fosse partilhado pelo partido filiado na Democracia Cristã que reconstruía a Europa.

Mas conviria ainda, para este tema das relações do Estado com a Igreja depois de 1974, notar que também aqui se verificou a ausência pública de afirmação ao que se passava nas colónias, no plano da doutrina, porque nem D. Sebastião de Resende, Bispo da Beira e padre conciliar do Vaticano II, 
foi lembrado e assumido, nem o foram o Bispo D. Manuel Vieira Pinto, de Nampula, que aqui liderara o movimento Para um Mundo Melhor, nem D. Eurico Dias Nogueira, depois Arcebispo de Braga, cuja Carta Fraterna, dirigida aos muçulmanos quando foi transferido de Moçambique para Angola, é um documento de alto valor histórico sobre as relações entre católicos e muçulmanos. Mas, sobretudo, D. Sebastião de Resende, que levou dezenas de anos a lutar contra as violações não apenas da dignidade humana, mas até das leis, que morreu em luta nos tribunais pela liberdade da palavra, cujas obras principais estão publicadas em livro chamado Profeta em Moçambique, não foi herdado pelo movimento de renovação do 25 de Abril.

Todavia, julgo que tem de considerar-se presente, em espírito, um facto a que atribuo significado, e foi a homilia de D. António Ribeiro quando, julgo que pela primeira vez, depois de elevado a Cardeal Patriarca, celebrou missa na Sé, com a presença do Presidente da República, Almirante Tomaz, e vários membros do Governo: a sua homilia foi a mais clara afirmação, de raiz conciliar, da separação entre a Igreja e o Estado.

D. António, que foi professor do ISCSP, tinha sido nomeado para suceder a D. Sebastião de Resende na Beira, depois da morte deste. Porém, nos termos da Concordata e do Acordo Missionário, o governo recusou a concordância à designação, e D. António foi mandado para Bispo auxiliar de Braga, de onde o Bispo auxiliar D. Manuel sairia para a Beira, lugar onde resistiu pouco tempo às dificuldades. Mas a palavra de D. António, cuja elevação o governo não previa, não foi ouvida sem que muitos recordassem as intervenções de D. Sebastião, que fora impedido de substituir na Beira, e continua presente em muitos que o recordam comovidamente, e com fidelidade: sou um deles.

O novo regime, anunciando a laicidade do Estado, renegociou a Concordata com respeito pela liberdade das confissões, e respeito devido à Igreja Católica. Mas existe um problema, esteja ou não na Constituição - e estava na de 33 -, que diz respeito à concepção da sociedade civil, e os textos constitucionais do Regime Corporativo traduziam no imperativo que obrigava o Estado a respeitar a moral tradicional do país, o que, na interpretação, sem divergências que recorde, dos constitucionalistas, significava a moral cristã.

Tem sido neste plano que se tornaram importantes as divergências da Igreja Católica portuguesa com o Estado laico que respeita. A primeira das 
questões que agitou o eleitorado e as diferenças de perspectiva entre cidadãos crentes e alguns não-crentes, foi a do aborto. Talvez seja razoável admitir que a lei foi encontrando razoabilidade cívica pacificadora, mas a incompatibilidade entre a doutrina da Igreja e o Estado é insanável.

Tem ligação com esta questão a doutrina católica do casamento, que tem relação indissolúvel com a concepção de recebimento e presença no acompanhamento dos filhos, e a divergência fundamental sobre a simplificação e facilitação do processo civil de dissolução do casamento, quer no que toca ao casamento católico, quer, pelas responsabilidades paternais, no que respeita às outras formas de casamento. Ainda, sempre no que toca à sociedade civil e à ética da comunidade, o casamento entre pessoas do mesmo sexo implantou um diferendo fundamental entre a doutrina da Igreja sobre o Sacramento da união entre homens e mulheres, e a utilização, não apenas semântica, do conceito secularmente consagrado nas próprias leis civis, para a união de pessoas do mesmo sexo, aproximando-se a questão inevitavelmente conexa da adopção a conceder a qualquer casamento, assim definido pela lei civil. Finalmente, na área da ética para a ciência da vida, uma pluralidade de problemas, em que se destaca a eutanásia, dividem Igreja e Estado, a primeira na defesa de uma concepção de valores que deram forma à sociedade civil, e a lei do Estado, pela doutrina da Igreja, não deve infringir. Para tentar sintetizar esta linha de problemas, recordarei que o antes chamado Tratado Constitucional, e agora modestamente chamado Tratado de Lisboa, rejeitou a referência aos valores religiosos cristãos no paradigma europeu, consagrando, por outro lado, o paradigma da investigação e ensino europeus, que aponta para uma sociedade da informação e do saber, mas omite a sabedoria como que consagrando, se a palavra pode aqui ser usada, o relativismo que envolve o Ocidente em geral. E aqui surge a questão fundamental da posição dos poderes políticos, dos Estados individualmente considerados, e das regionalizações, inter-estaduais como é o caso da União Europeia, perante a importância das religiões na definição de um projecto de futuro.

Num livro que ganhou circulação mundial, escrito por Huston Smith, com o título original “The World's Religions”, um dos críticos escreveu estas palavras, reproduzidas na apresentação da tradução portuguesa (2005) da editora 
Lua de Papel: "no preciso momento em que lê estas linhas, um pouco por todo o mundo haverá cristãos ajoelhados em preces, judeus a recitar a Tora, muçulmanos a rezar voltados para Meca, hindus a banharem-se nas águas sagradas do Ganges, monges budistas a meditar... Neste preciso momento, milhares de fiéis procuram na religião uma paz e um consolo que só a fé lhes consegue trazer".

Estas palavras podem surpreender todos os que apoiaram que o depois chamado Tratado de Lisboa omitisse qualquer referência aos valores cristãos que foram estruturantes da identidade europeia e ocidental, e que conduziram a sociedade civil da União Europeia, hoje em processo de crise, para um relativismo que perturba a esperança com que precisa de ser amparada e fortalecida a vontade de ultrapassar as violentas consequências do desastre financeiro e económico que nos atingiu.

Todavia, ao mesmo tempo que o relativismo e o desastre convergiam para a angustiante circunstância dos nossos dias, o interesse pelo islamismo multiplicou atenções, estudos, investigações, prospectivas, na área ocidental, e não pelas melhores razões.

De facto, o factor determinante foi o ataque de 11 de Setembro às Torres Gémeas de Nova York, a surpreendente acção de um grupo atípico a desafiar a superpotência mundial sobrante, obrigando à teorização agravada do terrorismo, à avaliação tardia do descontrolo das migrações que instalaram pelo menos dezoito milhões de crentes nos territórios dos Estados europeus, à reavaliação da inquietante evolução demográfica, e também ao que foi chamado eixo do mal pelo unilateralismo americano, quando soberanias de cultura dominantemente muçulmana se inscreveram na corrida da dispersão e titularidade das armas de destruição maciça.

A tese do choque das civilizações, devida ao universitário americano Samuel Huntington, reduziu a complexidade da circunstância mundial ao anúncio de um futuro de fundamentalistas e integristas a conduzirem a Humanidade para o caos, com a civilização ocidental em risco, e para alguns em trânsito para o desaparecimento. Do país que anunciou o fim da história, metodicamente definido como modelo de felicidade global, e traça americana, por Fukuyama, vinha a prospectiva do apocalipse, cujas conclusões amarguraram os últimos escritos de Huntington, perguntando-se, como americano, 
Who are we? (2005), talvez pelo risco das minorias que estavam a chegar ao poder, não tendo assistido ao triunfo de Obama.

Para tornar a circunstância mundial mais inquietante, o conflito agudo que alarmou os espíritos, e de seguida daria origem a graves envolvimentos militares de resultado incerto para os directamente envolvidos e também para os que inevitavelmente sofrerão os efeitos colaterais dos combates em curso, não incluiu no panorama das ameaças mais severas, nem os hindus a banharem-se nas águas sagradas do Ganges, nem os monges budistas a meditar. De facto, repôs a secular desavença das religiões que têm em Abraão o antepassado comum dos "Povos do Livro", como salientou o ilustríssimo Hans Küng, ao tornar claro o conceito com que orientou os estudos, investigações e conclusões dos seus tratados monumentais sobre o Judaísmo (1991), o Cristianismo (1994) e o Islão (2004), conceito resumido nestas palavras: "não há paz entre as nações sem paz entre as religiões. Não há paz entre as religiões sem diálogo entre as religiões. Não há diálogo entre as religiões sem normas da ética global. Não há sobrevivência no nosso globo sem uma ética global, uma ética mundial compartilhada por crentes e não crentes".

A premissa ética do diálogo tem sido a busca em que consome a inteligência, a vida, e a devoção, e o facto é que, ao contrário, a realidade fez explodir conflitos militares, ou atípicos como o terrorismo, ou entre poderes e políticas que também, como aquele, inscrevem valores religiosos no seu conceito estratégico, como se passa no Iraque, no Paquistão, na disputa Israel - Palestina, e assim por diante. Colocar o diálogo no lugar do combate, e sobretudo retirar Deus do campo de batalha, espera pelo poder encantatório de vozes capazes de restaurar e assumir a liderança das opiniões das sociedades civis, mas também espera pela serenidade universitária, empenhada numa sociedade mundial de informação, do saber, e também da sabedoria, isto é, dos valores, do repúdio do relativismo, do poder da palavra contra a palavra do poder.

Uma tarefa sobretudo urgente, no que toca à universidade, porque o regresso ao estudo urgente do islamismo não pode negar a importância dinamizadora dos conflitos armados, dos atentados, do terrorismo global, da complexidade da relação entre as sociedades civis ocidentais estruturadas ao longo dos séculos e as multidões de imigrantes recebidas descontrolada- 
mente, sem política de integração, sem política de assimilação, sem política de justiça social.

O facto é que, regressando à linguagem tão expressiva de Hans Küng, quando toda a inquietação e interesse suscitado pelo islamismo cresce, é a imagem do inimigo que regressa e condiciona muitas das perspectivas em curso, com lembrança do paradigma do império Árabe a ultrapassar em inquietação o paradigma do Islão como religião universal, com incertezas sobre que tipo de Islão pretendem os muçulmanos, pan-islamismo, pan-arabismo, islamismo, socialismo, secularismo, isto é, sobre o futuro da ordem estatal e da política islâmica: o tema emergente é o da passagem da imagem do inimigo à imagem da esperança (Küng).

Recordei que a imagem do adversário, no ensinamento de Hans Küng, esteve secularmente nas premissas da curiosidade, ou académica, ou religiosa, ou sobretudo política, um facto visível na história da Península Ibérica. Não obstante a sabedoria com que os reis da reconquista "manifestaram ter uma clara noção sobre o interesse da actividade económica dos mouros, pelo que não praticaram uma política de extermínio das suas comunidades", como vem anotado na recente e excelente História de Portugal (2009) coordenada por Rui Ramos, também fica ali relembrado que "a intolerância religiosa e a agressividade mútuas entre cristãos e muçulmanos acentuou-se neste período" (pg. 43) e tal conflito manter-se-ia nas várias fases da expansão para o oriente. Lembro isto por justiça para com a esperança dos que nesta data julgam a indispensável definição do paradigma a que Küng chamou "projecto de uma ética mundial" e que, na área da investigação e do ensino, significa servir a sociedade da informação e do saber, sem esquecer a sabedoria dos valores de que a luta política, passada e tragicamente actual, afecta as relações entre os povos do Livro. Não se trata de fundir crenças, porque, como foi bem observado, "em termos históricos, a missão cristã para o Islão não teve qualquer sucesso, como a missão muçulmana para o Cristianismo foi e continua a ser infrutífera" (Küng). Mas, na circunstância do globalismo, sem governança, numa data em que finalmente todas as áreas culturais do mundo falam com voz própria, o grande projecto da ONU foi encontrar um paradigma ético comum que pudesse colocar o diálogo, com a sua metodologia dirigida ao consenso diplomático da razoabilidade, no 
lugar dos conflitos armados em que se pretende que a vitória reduza ao silêncio a argumentação do adversário. Mas a experiência, que tanto se afastou dos projectos da ONU, e que hoje está semeada de conflitos armados em que os conceitos estratégicos em competição recorrem a valores religiosos, por vezes ao confronto com ideologias que apenas são democráticas, ou com interesses apenas cobertos pelas razões de Estado, mostra que sem uma ética comum, paradigma orientador de uma ordem jurídica pacifica e globalizada, não será possível reorientar a governança que nos falta. Recentemente, a tese doutoral de Eva-Maria von Kemnitz fortalece a convicção de que o diálogo é o método elegível, que as circunstâncias, designadamente mediterrânicas, o exigem, que a experiência portuguesa vivida apoia um saber feito de experiência. Devemos-lhe este serviço. O qual também é um passo para a formulação, a definir e aceitar, de uma ética comum. Para conseguir um objectivo, prévio a toda a esperança de governança pacífica do globalismo, que é recolher a fé aos corações e retirar Deus do campo de batalha. A República, o Estado laico, não podem ignorar a complexidade crescente das comunidades que, na Europa em particular, no Ocidente em geral, nos regionalismos em multiplicação, professam - a maneira religiosa com que, na certeira visão de Huston Smith, em cada monumento procuraram "uma paz e um consolo que só a fé lhes consegue trazer". O grande desafio, no multiculturalismo do século Xxi, são as fracturas da sociedade civil, cujo risco o Estado laico não pode ignorar. 